\title{
1 Animals in flow - towards the scientific study of intrinsic reward in animals
}

2 Sara Hintze ${ }^{1, *, \dagger} \&$ Jason R. Yee $e^{2, \dagger}$

$3{ }^{1}$ Institute of Livestock Sciences, Department of Sustainable Agricultural Systems, University of Natural

$4 \quad$ Resources and Life Sciences, Gregor-Mendel-Strasse 38, 1180 Vienna, Austria

$5 \quad{ }^{2}$ Institute of Animal Welfare Science, Department for Farm Animals and Veterinary Public Health,

6 University of Veterinary Medicine Vienna, Veterinärplatz 1, 1210 Vienna, Austria

$7 \quad *$ Author for correspondence

$8 \quad$ Email: sara.hintze@boku.ac.at; Tel.: +4367762366020

$9 \quad$ Email: jsn.r.yee@gmail.com; Tel.: +43 664602576994

$10 \dagger$ Authors contributed equally to this work.

\section{ABSTRACT}

12 The concept of flow, a state of complete absorption in an intrinsically rewarding activity, has played a 13 pivotal role in advancing notions of human well-being beyond minimising suffering towards promoting 14 flourishing and thriving. While flow has played a fundamental role in human positive psychology, it has not 15 yet been explored in non-human animals, leaving an enormous void in our understanding of intrinsic 16 motivation in animals. As ethology and related fields keep progressing in uncovering complex cognitive and 17 affective capacities of non-human animals, we propose the time is ripe to translate the concept of flow to animals. We start by embedding flow in the topic of intrinsic motivation and describe its impact on positive concepts discussed in the animal literature. Next, we derive experimental approaches in animals from the canonical characteristics of flow in humans and provide guidelines for both inducing and assessing flow by focusing on two characteristics that do not necessarily depend on self-report, namely resistance to distraction and time distortion. Not all aspects of the human flow experience are (yet) translatable, but those that are may improve quality of life in captive non-human animals.

Key words: animal welfare, positive psychology, optimal experience, affective states, motivation, play, curiosity, agency, effectiveness, contrafreeloading, Eureka moment. 
29 I. Introduction

30 II. Why study flow in non-human animals?

(1) Methodological advantages for the study of flow in non-human animals

(2) Advancing the field of positive animal welfare

III. Integrating the concept of flow into the archipelago of related concepts in animal research

(1) Play

(2) Curiosity

(3) Agency and competence

(4) Effectiveness

(5) Contrafreeloading

(6) Eureka or Aha! moment

40 IV. Towards the study of flow in non-human animals

(1) Flow induction

(a) Environmental enrichment and flow induction

(b) Chronic stress

(c) Flow proneness and personality traits

(2) Flow assessment

(a) Resistance to distraction

(i) What to consider

(b) Distortion of time

(i) What to consider

(3) Identifying the behavioural, physiological and neurophysiological signature of flow 5

VII. References 


\section{INTRODUCTION}

55 Humans have an intuitive understanding of engaging in an activity out of pure enjoyment, because the very

56 engagement itself is fun not necessarily because it results directly in some desired outcome. Many people

57 will spend money, sometimes a lot of it, or make painful sacrifices, to engage in activities like rock

climbing, surfing, or golf. While there are many ways for humans to access these kinds of experiences, there are very few that we can provide to non-human animals in our custody. In companion animals like dogs, we train them with treats or provide them with toys or chewing material. We provide farmed animals with

61 access to resources like bedding material, brushing stations or objects to manipulate. Animals kept in the lab are commonly motivated to perform tests with rewards of fruit juice, sugar pellets, etc. However, these examples are likely insufficient in stimulating animals to levels of enjoyment that humans attain through recreational activities. Can we provide animals with the same access to a sense of enjoyment that we as humans value so dearly?

Human motivational psychology proposes that the pursuit of happiness can be fuelled in two ways. The first involves a motivational stance centred on achieving extrinsically rewarding outcomes that play an instrumental role in aiding survival. Early theories of human motivation proposed that all behaviours are motivated by basic physiological drives such as hunger, thirst, and sex (Deci \& Ryan, 2009; Freud, 1962; Hull, 1943). However, researchers began to uncover phenomena that revealed the insufficiency of drive theories, for example, noting that rats with their basic drives fulfilled would still inexplicably cross electrified grids to explore a new area of the cage (e.g. Dashiell, 1925; Nissen, 1930). Reviewing this evidence, White (1959) introduced what has become a second way of understanding motivation, as deriving from intrinsic psychological sources. In contrast to extrinsic motivation, intrinsic motivation leads to the performance of an activity that is interesting and rewarding for its own sake. Decades of systematic experimentation in humans has provided a clear picture of the bidirectional causal relationship between competence and autonomy on the one hand, and intrinsic motivation on the other, with each augmenting the other in a feedforward manner (Diener et al., 1999; Ryan \& Deci, 2000; Ryff, 1989; White, 1959). Findings from both cross-sectional (Ryan et al., 1999; Ryan \& Deci, 2000) and longitudinal (Sheldon \& Kasser, 1998) studies suggest that while fulfilment of intrinsic goals enhances well-being, fulfilment of extrinsic goals does not, or does so to a lesser extent. Moreover, when people performing intrinsically motivating 
activities are given extrinsic reward for their performance, this tends to undermine their motivation to continue rather than reinforce it (Deci, 1971). Thus, a strong case can be made that, at least for humans, the cultivation of intrinsic motivation is a key determinant of well-being.

Can we be sure that the distinction between intrinsic and extrinsic motivation is more than a pedantic one? If the distinction is meaningful and consequential, careful experiments to elucidate proximate mechanistic differences should be able to recapitulate it. However, while there are ample mechanistic studies on extrinsic motivation, there are few that target intrinsic motivation. The few studies employing neuroimaging to reveal patterns of brain activation in response to mild intrinsic motivation (e.g. curiosity) have repeatedly shown activity in the striatum during times subjects felt more intrinsically motivated in the task (Gruber, Gelman \& Ranganath, 2014; Kang et al., 2009; Murayama et al., 2010). Striatal activity is a hallmark of reward processing and its presence during the performance of intrinsically motivating tasks is a strong indication that both types of motivation share overlapping mechanisms. However, in the only study to directly test differences in brain activation as a function of the presence or absence of intrinsic motivation, intrinsic motivation was associated with unique activation of the anterior insular cortex (AIC) as well as heightened connectivity between the AIC and striatum (Lee et al., 2012; Lee \& Reeve, 2013). The AIC is thought to contribute to the processing of bodily satisfaction (Goldstein et al., 2009; Lee \& Reeve, 2017; Naqvi \& Bechara, 2009) and subjective feelings (Craig, 2009; Damasio, 1999; Lee \& Reeve, 2017). Its unique involvement during intrinsic, but not extrinsic, tasks indicates that the distinction between the two types of motivation is worth further pursuit.

One of the best-known concepts driven by intrinsic motivation is the concept of flow or optimal experience. Flow is a state of complete absorption or engagement in an autotelic activity, an activity that one finds rewarding intrinsically irrespective of any end-product or extrinsic benefit. As such, it has been a paragon for research on well-being and positive psychology of human flourishing, thriving, and optimal experience (Csikszentmihalyi, 1990). Research subjects on flow include rock climbers (MacAloon \& Csikszentmihalyi, 1983; Schattke et al., 2014), dancers (Bernardi, Bellemare-Pepin \& Peretz, 2018) and other athletes (Swann et al., 2012), chess players (Tozman, Zhang \& Vollmeyer, 2017), musicians (Chirico et al., 2015) and surgeons (Mulligan, 2016) who describe their state of complete absorption and full involvement as being "in flow" or, in more colloquial terms, as being "in the zone". While much of the scholarly work on flow comes 
from western-educated, industrialised, rich, democratic (WEIRD) contexts, continued investigation outside these contexts is revealing that the core features of the experience are widespread, present across cultural contexts and perhaps throughout history as well. Descriptions of states similar/indistinguishable to flow have been reported outside WEIRD contexts while engaged in activities as diverse as reading religious texts (Han, 1988), riding motorcycles in a Japanese parade (Sato, 1988), herding sheep on horseback, rugweaving, or gardening (Csikszentmihalyi \& Asakawa, 2016). Eastern philosophical doctrines such as the Bhagavad Gita and writings of Taoist master Chuang Tzu discuss concepts that bear a striking resemblance to flow (Csikszentmihalyi \& Asakawa, 2016).

Entering a flow state requires striking a balance between 'perceived action capacities' or skill, and 'perceived action opportunities' or challenge (Fig. 1; Csikszentmihalyi, 1975, 1990). The balance is not static, but rather unfolds dynamically over the course of an activity by applying effort to a series of small and just-manageable goals, processing feedback about progress, and adjusting action according to the feedback (van der Linden, Tops \& Bakker, 2021). The goals provide benchmarks for feedback (Csikszentmihalyi, 1975, 1990). Imbalance leads to two types of psychological perturbation. If challenge outweighs skill, the resulting psychological experience can be frustration or anxiety because we realise that we cannot meet the requirements of the task (Csikszentmihalyi, 1990). If, on the other hand, skill outweighs challenge, the resulting psychological experience can be boredom (Csikszentmihalyi, 1990). However, it is important to be aware that boredom occurs not only when challenges are too simple, but also when they are too hard since in both cases the individual fails to engage with the task (Danckert \& Eastwood, 2020). Harmony with the activity and a feeling of control are important for deriving satisfaction from the activity and thus to achieving the flow state.

While we and others conceptualise flow as a state that unfolds over the course of a bout of activity, the dynamic interplay between skill and challenge can also unfold over an ontogenetic timescale. When skill increases across ontogeny the individual gradually develops mastery within the given domain of challenge. While flow experiences are thought to facilitate and accelerate mastery, it remains in question whether they are necessary to achieve it.

So far, studies on flow have all been conducted with human subjects; to our knowledge no empirical data on flow in non-human animals exist. Here we propose translating the concept of flow to non-human animals $(a)$ 
to explore flow from a broader perspective than just the human one and $(b)$ to provide another approach to

139 improve animal welfare. We start by describing how the study of flow in non-human animals may be a quantum leap forward for both positive psychology and positive animal welfare and how it is related to other

141 concepts in animal research, namely play, curiosity, agency and competence, effectiveness,

142 contrafreeloading and the Eureka moment. We continue by describing methodological approaches to assess

143 flow. To this end, we first characterise flow in humans as a basis to identify which of these characteristics

144 have the potential to be applied to non-human animals. We suggest how to study the concept of flow in 145 animals by differentiating between flow induction and flow assessment. Both components are presented 146 with practical considerations and a discussion of their potential risks and benefits.

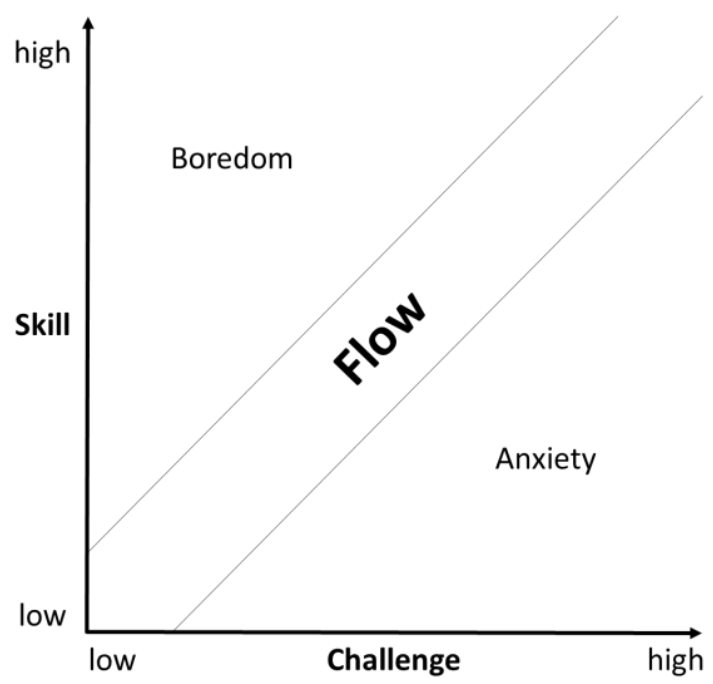

Fig. 1. Matching challenge and skill to achieve flow. Adapted from Csikszentmihalyi $(1975,1990)$. 


\section{WHY STUDY FLOW IN NON-HUMAN ANIMALS?}

151

152

153

154

155

156

157

\section{(1) Methodological advantages for the study of flow in non-human animals}

Studies of flow in humans have mostly relied on self-report including the Flow

Questionnaire, the Experience Sampling Method as well as scales capturing flow as a multidimensional state-trait variable (reviewed in Moneta, 2012). While self-report has clear advantages, there are also several limitations, e.g. report biases (Fisher, 1993) or the differentiation from other constructs such as motivation or mindfulness (e.g. van der Linden et al., 2021; Reid, 2011). If we aim to investigate flow in the animal kingdom, different methodological approaches, i.e. on a behavioural, physiological, neural or cognitive level, will be required. These approaches may not only enable us to study flow in non-human animals but may also broaden our understanding of the concept by looking at it from different perspectives. Moreover, the methodological approaches used to study flow in animals may also be translated back to humans, which may stimulate research on the convergent validity of the methods used so far, i.e. whether and to what extent commonly used indicators are related to the new indicators intended to measure the same construct, namely flow. Thus, studying flow in non-human animals will not only provide deeper knowledge on intrinsic motivation drawn from a broader range of species, but will also advance the methodological study of flow in humans.

\section{(2) Advancing the field of positive animal welfare}

The desire to study flow in non-human animals derives also from a desire to improve their lives. Until the beginning of this millennium, animal welfare science has predominantly focused on how to avoid and assess negative experiences including stress and pain. More recently, the study of positive experiences has gained momentum (Mellor, 2012; Rault et al., 2020; Yeates \& Main, 2008), reflecting society's expectations of how we should keep and 
treat animals (Rault et al., 2020; Vigors, 2019). The unique focus of positive welfare research can be characterised by a desire to describe the conditions under which animals thrive, not simply survive.

While the vast literature on motivation deals with extrinsic goals, research on intrinsic motivation in non-human animals is almost completely lacking. Considering the fundamental role intrinsic motivation has been shown to play in creating subjective well-being (Cantor \& Sanderson, 1999; Diener, 2000; Diener et al., 1999), happiness (Diener, 2000; Diener et al., 1999), and a life worth living (Csikszentmihalyi, 2006) in humans, it may be fair to say that these topics have yet to be truly and systematically investigated in non-human animals. While scholarship on effectiveness (e.g. Franks \& Higgins, 2012), agency (e.g. Špinka, 2019; Špinka \& Wemelsfelder, 2018) and competence (e.g. White, 1959) indicate an interest in understanding and providing positive animal welfare, the near-complete abstention from acknowledging the potential for intrinsic motivation in animals has left the field in a state of arrested development. Introducing the concept of flow to non-human animals may add a promising novel layer to the emerging field of positive animal welfare.

\section{INTEGRATING THE CONCEPT OF FLOW INTO THE ARCHIPELAGO OF RELATED CONCEPTS IN ANIMAL RESEARCH}

The concept of flow stems from the psychology of human well-being and flourishing. For clarity, we refer to flow as the state one enters during an autotelic activity that offers repeated opportunities for skill and challenge to come into balance. An autotelic experience is one in which the subject having it feels intrinsically rewarded by having it and continues to do it in the absence of extrinsic reward. Intrinsic motivation is the drive to engage in a set of actions for their own sake rather than for the sake of an indirect gain. In animal welfare science, flow has been mentioned by few authors (e.g. Arhant et al., 2020; Clark, 2011, 2017; Meehan \& 
Mench, 2007; Špinka, 2019), and empirical data do not exist. We do not claim that flow is an isolated concept, but rather argue that it forms part of an archipelago of related themes that have been studied theoretically and/or empirically in non-human animals and that link to the concept of flow. Here we provide a brief overview of these related themes and conclude that while there are many concepts relevant to the study of flow already discussed in the literature, we propose that they are necessary but not sufficient for a full-blown flow experience.

\section{(1) Play}

Play is likely the first activity which comes to mind when considering flow and both are often linked in the literature as much of the seminal work on flow is set against a backdrop of play. While they are undoubtedly linked, play refers to an activity while flow refers to the mindbody state experienced when the activity takes on a certain dynamic (Fig. 1). More importantly, however, we contend that both should remain conceptually distinct since play does not necessarily lead to flow and flow can be induced by activities other than play. Although it is widely accepted that play is enjoyable in both human (Burghardt, 2010; Harris, 1978) and non-human animals [Held \& Špinka, 2011; Vanderschuren, 2010, but see BloisHeulin et al. (2015) for a different opinion on adult play], this enjoyment can arise through mechanisms independent of flow. For example, play can be enjoyable because of the social component many games have or because one feels comfortable with the rules and just wants to focus on something other than daily routine. Furthermore, a prerequisite hallmark of flow - being consistently challenged - is not necessary to enjoy playing. Conversely, flow can emerge through activities other than those typically categorised as 'play', such as solving maths problems, reading, or performing surgery. Thus, both play and flow may precipitate each other, but neither is absolutely necessary for the other to be invoked. While both often 
work together in the course of daily life, we believe there is utility in keeping the terms conceptually distinct.

\section{(2) Curiosity}

As with any wide-ranging concept, there is no universal definition of curiosity but rather a variety of definitions with different emphases and an associated taxonomy of curiosityrelated topics, including exploration, reinforcement learning, latent learning, and play (Kidd \& Hayden, 2015). Different descriptions of curiosity, including to explore for the sake of exploring (Kashdan et al., 2018) and to reduce a perceived gap in knowledge (Loewenstein, 1994), emphasise a core information-seeking element to curiosity. A common thread linking curiosity and flow is that both are often described as arising out of intrinsic motivation. However, whereas curiosity is a basic motivational state, flow is the state that results from motivations that have been continuously and iteratively satisfied. Their close conceptual relationship makes it plausible that they frequently play important roles in regulating each other. In support of this, curiosity has been shown to trigger and maintain a flow state in humans (Lavoie \& Main, 2022; Schutte, 2020).

\section{(3) Agency and competence}

There is no doubt that agency (Welzel \& Inglehart, 2010) and autonomy (Baluku, Kikooma \& Otto, 2018; Holliman, Revill-Keen \& Waldeck, 2020) are relevant for human well-being. While philosophers still debate whether or not animals are agents (Jamieson, 2018; Steward, 2009), animal welfare scientists have begun to consider the concept (Rault et al., 2020; Špinka, 2019; Špinka \& Wemelsfelder, 2018). In this context, agency is defined as active engagement with the environment whose aim is to gather knowledge and build competencies 
to prepare for novel challenges in the future (Špinka \& Wemelsfelder, 2011, 2018). As such,

250

251

252

253

254

255

256

257 agency is very close related to the concept of curiosity.

One difference between agency and flow is that entering a flow state requires a balance between skill and challenge whereas a sense of agency can be obtained regardless of challenge level. For example, provision of rooting material or other enrichment in animals' housing environments, if frequently provided and regularly changed, may enhance a sense of agency, but will only induce flow if the use of the enrichment is linked with challenge matched to skill level as in the case of some cognitive enrichment items designed for primates (Gray et al., 2018). This difference also holds true for competence. Only if an animal can apply their competence to a challenging activity that matches their competence can they access a flow state. Agency and competence are often viewed as means to cope with negative situations in a more resilient manner, e.g. to be better prepared for stressful situations like regrouping, transport for slaughter, etc. Complementarily, we propose enhancing agency and competence so that animals can master a challenging but intrinsically rewarding task. Exercising agency and thus building competences or skills are a precondition for experiencing flow, necessary but not sufficient. We argue that flow is something more than expressing agency - it is developing and applying increasing competences to increasing challenges in a manner that feels effortless.

\section{(4) Effectiveness}

Effectiveness is an approach to the study of motivation asserting that humans and other animals aim to be successful in three domains (Franks \& Higgins, 2012): achieving desirable outcomes (value effectiveness), developing a firm grasp on reality (truth effectiveness) and having a sense of control over outcomes (control effectiveness). Like flow, effectiveness is not an isolated concept. Agency (see Section III.3) and contrafreeloading (see Section III.5), 
for example, are means to achieve both truth and control effectiveness. Similar to flow, challenges are crucial since they facilitate engaging in effectiveness as long as they are not too frequent, unpredictable or unmanageable (Franks, 2012). The relevance of challenge is thus a commonality for both the concept of flow and effectiveness. In addition, both flow and effectiveness share an emphasis on process (Franks, 2012). However, the difference between the two hinges on the idea that, for effectiveness the focus is still on what is achieved, i.e. a desired outcome, whereas for flow the focus is on the activity itself independent of the final outcome or end product resulting from having performed the activity. Further research into both concepts may shed light on the extent to which the desired outcomes of effectiveness, truth and control, are related to the intrinsic motivation to engage in an activity for its own sake.

\section{(5) Contrafreeloading}

Contrafreeloading refers to phenomena in which an animal is willing to work for food or other resources when the same resource is freely available (Inglis, Forkman \& Lazarus, 1997; Osborne, 1977). It has been the subject of decades of research and has been described in a range of different species including animals housed in zoos [e.g. grizzly bears (Ursus arctos horribilis, McGowan et al., 2010) and maned wolves (Chrysocyon brachyurus, da Silva Vasconcellos, Adania \& Ades, 2012)], in laboratories (e.g. rats; Jensen, 1963) or on farms [e.g. pigs (Sus scrofa, de Jonge et al., 2008) and cattle (Bos taurus taurus, Van Os et al., 2018)]. For animals living in changing environments, the functional advantage of contrafreeloading is to gather information for the future (Inglis et al., 1997), stressing the link with effectiveness and competence resulting from agency.

The phenomenon of contrafreeloading includes an important aspect of flow, namely developing resistance to distraction, or in this case ignoring the freely available resource. 
However, we do not necessarily view all contrafreeloading phenomena as flow-inducing

300

301

302 since in some contexts the effort to achieve access to the resource leads to rote repetition of the same behaviour (e.g. bar pressing in rats; Jensen, 1963) or exploration (e.g. foraging for food in pigs; de Jonge et al., 2008) rather than mastering a challenge. Nevertheless, studies on contrafreeloading may generate ideas for how to construct special devices that allow the degree of challenge to be systematically modulated according to the changing competence/mastery of the individual and thus to enter a flow state.

\section{(6) Eureka or Aha! moment}

The Eureka or Aha! moment refers to the experience of suddenly and unexpectedly arriving at a solution to a previously intractable problem. In contrast to a more deliberate course of problem-solving, it is accompanied by "a sense of surprise and a burst of positive emotions spanning from satisfaction to euphoria” (Sprugnoli et al., 2017, p. 101). Due to its unpredictable nature, studying the Eureka moment is challenging, but first attempts have been made to identify behavioural and physiological signatures in non-human animals. In a yoked control experiment, Hagen \& Broom (2004) found that heifers who learned to press a panel to obtain access to a food reward had higher heart rates and tended to show more vigorous behaviour at the very moment in which they learned the contingency. This finding was interpreted as a first indication of an emotional reaction to the heifers' own learning performance. It was only a decade later that Broom (2015) used the term Eureka effect when referring to this study. McGowan et al. (2014) aimed to identify the Eureka moment in dogs trained on a problem-solving task, again using a yoked control experiment. They found behavioural signs of excitement, e.g. increased tail-wagging, in the experimental dogs that could control their access to rewards but not in control dogs. 
323 The primary difference between the Eureka moment and flow is that they occur on different

324 timescales. Whereas the Eureka moment is an instant of realisation of how something works,

325 flow is a longer-lasting state of mastering a challenge and enjoying the process of doing so.

326 However, both have in common that the subject needs to realise the connection between their

327 behaviour and the consequent outcome. We speculate that flow might thus be accompanied

328 by a series of 'Eureka micro-moments', one for every different level of challenge, which are

329 necessary for experiencing flow. We propose that achieving a full-blown flow state requires

330 (at least) one Eureka moment for every new challenge that needs to be overcome, and

331 therefore many Eureka moments for the final flow state to be achieved. 


\section{TOWARDS THE STUDY OF FLOW IN NON-HUMAN ANIMALS}

334 Research on flow in humans has always relied on self-report, mainly using the Flow Questionnaire, the Experience Sampling Method, and standardised scales that emphasise various aspects of flow (Moneta, 2012). While research relying on self-report has advantages, not the least of which are convenience and feasibility, it also has drawbacks, such as report biases (Fisher, 1993). We propose that the study of flow in animals should be approached similarly, namely with an expectation of both advantages and limitations. At least at the start, many of the subjective, experiential aspects of flow in humans will not be accessible to investigation in animals. For example, the subjective feelings of heightened control and effortlessness reported by humans in flow (Csikszentmihalyi, 1975, 1990) seem empirically out of reach at present. However, we believe such limitations should not preclude the study of flow in animals altogether. Stimulating research on flow in animals can only deepen our overall understanding of the concept with the hope of using it to improve positive animal welfare science.

A large body of work in humans has led to a crystallised understanding of what it takes, vis$a$-vis both the individual and the activity, to achieve flow: (i) a balance between the individual's skill and the degree of challenge or difficulty provided by the activity; (ii) clear goals while performing the activity such that the individual knows exactly what to do; and (iii) immediate feedback to allow ongoing monitoring of performance (Csikszentmihalyi, 1975, 1990; van der Linden et al., 2021). These characteristics can be thought of as preconditions for a flow experience. In addition, researchers have identified a consistent set of subjective, experiential aspects that characterise the phenomenology or outcomes of a flow experience (also summarised in Table 1): $(i)$ intense and focused concentration on the present activity such that the surrounding world seems to fade to the background; (ii) merging of action and awareness such that there is a sense of perceived automaticity; (iii) loss of 
awareness of the self in that everyday worries and fears vanish; (iv) a sense of control and competence such that the demands of the task must be within reach but not totally predictive of the outcome (i.e. a 'stretch goal'); ( $v)$ a distortion of time in which time seems to pass

361 faster than normal (but be aware that also the opposite might be true in that time seems to 362 stand still); ( $v i)$ a feeling that one's action is effortless; and (vii) a sense of intrinsic reward in which the end goal is only an excuse for engaging in the process (Csikszentmihalyi, 1975,

364 1990; Csikszentmihalyi, Abuhamdeh \& Nakamura, 2014; van der Linden et al., 2021).

365 We propose that these characteristics can be classified according to two categories. The first 366 is flow induction, i.e. how to induce a state of flow; the second is flow assessment, i.e. how to 367 detect and assess a flow experience. Below we discuss both flow induction and flow assessment based on the flow characteristics described for humans and propose approaches to study flow empirically in non-human animals (Table 1). 
Table 1. Flow characteristics and their relevance for studying flow in non-human animals.

\begin{tabular}{|c|c|c|c|c|c|}
\hline Flow characteristic ${ }^{1}$ & Description & $\begin{array}{l}\text { Precondition } \\
\text { or } \\
\text { outcome }^{2} \text { ? }\end{array}$ & $\begin{array}{l}\text { Relevant for flow } \\
\text { induction or flow } \\
\text { assessment? }\end{array}$ & $\begin{array}{l}\text { Translatable to } \\
\text { non-human } \\
\text { animals? }\end{array}$ & $\begin{array}{l}\text { Additional considerations for translating to } \\
\text { non-human animals }\end{array}$ \\
\hline $\begin{array}{l}\text { Match between skill and } \\
\text { challenge }\end{array}$ & $\begin{array}{l}\text { Challenge must fit to the } \\
\text { individual's skills and must } \\
\text { dynamically adapt to improved } \\
\text { skills due to repetition of the } \\
\text { task; one can make full use of } \\
\text { whatever skills are required. }\end{array}$ & Precondition & Flow induction & Yes & $\begin{array}{l}\text { Consider the ecological niche of the species as } \\
\text { well as breed and individual differences. }\end{array}$ \\
\hline Well-defined goals & $\begin{array}{l}\text { One knows what has to be done; } \\
\text { goals provide benchmark for } \\
\text { feedback. }\end{array}$ & Precondition & Flow induction & Yes & $\begin{array}{l}\text { Define intermediate goals and consider the size } \\
\text { and speed of each step to reach the intermediate } \\
\text { goals. }\end{array}$ \\
\hline $\begin{array}{l}\text { Clear and immediate } \\
\text { feedback on progress }\end{array}$ & $\begin{array}{l}\text { Ongoing monitoring of } \\
\text { performance and evaluation of } \\
\text { feedback (not necessarily } \\
\text { conscious). }\end{array}$ & Precondition & Flow induction & Yes & $\begin{array}{l}\text { Consider the feedback you want to give and how } \\
\text { to give it promptly throughout the activity. }\end{array}$ \\
\hline $\begin{array}{l}\text { Heightened focus and } \\
\text { concentration }\end{array}$ & $\begin{array}{l}\text { Intense and focused } \\
\text { concentration on the present } \\
\text { activity; attention is intensively } \\
\text { focused on a limited stimulus } \\
\text { field. }\end{array}$ & $\begin{array}{l}\text { Precondition } \\
\text { and outcome }\end{array}$ & Flow assessment & Yes & $\begin{array}{l}\text { Assess resistance to distraction: ability to ignore } \\
\text { increasingly attractive distractors (e.g. strange } \\
\text { noises, moving objects, food rewards) will } \\
\text { indicate the likelihood to which the individual is } \\
\text { in flow. Beware of different concepts where the } \\
\text { individual is also resistant to distraction, } \\
\text { including obsession, addiction and stereotypic } \\
\text { animal behaviour. }\end{array}$ \\
\hline $\begin{array}{l}\text { Merging of action and } \\
\text { awareness }\end{array}$ & $\begin{array}{l}\text { Some aspects of the activity are } \\
\text { performed in an automatic way; } \\
\text { one is aware of the action but not } \\
\text { of the awareness itself. }\end{array}$ & $\begin{array}{l}\text { Precondition } \\
\text { and outcome }\end{array}$ & Flow assessment & $\begin{array}{l}\text { Not yet; self- } \\
\text { report required }\end{array}$ & \\
\hline $\begin{array}{l}\text { Reduced self-reflection } \\
\text { and absence of worrying }\end{array}$ & $\begin{array}{l}\text { One is not preoccupied with } \\
\text { thinking about oneself; levels of }\end{array}$ & Outcome & Flow assessment & $\begin{array}{l}\text { Not yet; self- } \\
\text { report required }\end{array}$ & \\
\hline
\end{tabular}


worrying, are low.

\begin{tabular}{|c|c|c|c|c|c|}
\hline $\begin{array}{l}\text { Heightened sense of } \\
\text { control and competence }\end{array}$ & $\begin{array}{l}\text { Understanding how one's } \\
\text { behaviour affects the situation. } \\
\text { No worry about lack of control. }\end{array}$ & Outcome & Flow assessment & $\begin{array}{l}\text { Not yet; self- } \\
\text { report required }\end{array}$ & \\
\hline Distorted sense of time & $\begin{array}{l}\text { During flow time seems to stand } \\
\text { still, but post-hoc it seemed to } \\
\text { fly. }\end{array}$ & Outcome & Flow assessment & Yes & $\begin{array}{l}\text { Assess time distortion by applying a Temporal } \\
\text { Bisection Task or Peak Procedure. Consider that } \\
\text { flow leads to a sense of 'time flying by' but also } \\
\text { 'time standing still' and that it is unknown how } \\
\text { long the time distortion lasts when tested after } \\
\text { the flow experience has ended. }\end{array}$ \\
\hline Effortlessness & $\begin{array}{l}\text { Perceived mental effort is low } \\
\text { while objective effort may be } \\
\text { high. }\end{array}$ & Outcome & Flow assessment & $\begin{array}{l}\text { Not yet; self- } \\
\text { report required }\end{array}$ & \\
\hline Sense of intrinsic reward & $\begin{array}{l}\text { Activity is performed for its own } \\
\text { sake; no external reward needed; } \\
\text { intrinsic motivation. }\end{array}$ & Outcome & Flow assessment & $\begin{array}{l}\text { Not yet; self- } \\
\text { reporting } \\
\text { required }\end{array}$ & \\
\hline
\end{tabular}

$371 \quad{ }^{1}$ Based on Csikszentmihalyi (1975, 1990), van der Linden et al. (2021) and Harris et al. (2017).

$372{ }^{2}$ We chose the term outcome here for the sake of simplicity. This term refers either to the phenomenology of flow or to the outcome this experience leads to. 
374 A critical factor in inducing flow is finding the right balance between the skills and abilities of a subject and the challenge of the task they are faced with (Csikszentmihalyi, 1975, 1990). Striking this balance is the prerequisite to enter a flow state. If the task is too trivial, a subject is likely to lose focus and to become bored. If, on the other hand, it is too difficult, it may cause anxiety or frustration and, if the subject does not manage to engage with the task, they may become bored as well. The level of the task needs to be constantly adapted to the subject's skills that are likely to improve through repetition of the task. In other words, “challenge and skill chase each other" (Špinka \& Wemelsfelder, 2018, p. 45), rendering the task highly dynamic and emphasising the importance of tailoring it to the individual. Adapting the challenge to the individual is relevant for both choosing the initial degree of task difficulty as well as the speed and degree to which the challenge is adapted from one level to the next to match skill level, i.e. whether the animal advances in quick or slow steps or in small or large steps. It is important to note, however, that the tuning of challenge and skill level for the purpose of striking a precise balance between the two is likely to be dependent on the context of the flow-induction experiment, determined by factors relating to the animal, the activity, or the animal's performance of the activity.

The range of flow-inducing activities in humans is large, including a variety of sports (Schattke et al., 2014), chess (Tozman et al., 2017), performing surgery (Mulligan, 2016), playing music (Chirico et al., 2015) or even reading a book (Thissen, Menninghaus \& Schlotz, 2018). If we consider non-human animals with very different sensory and perceptual capacities, the variety of activities that induce flow will probably be even larger. Certain characteristics of the species need to be considered, e.g. their cognitive abilities, whether they are relatively neophilic or neophobic, whether they are a prey or predator species, and whether they are eager to be physically active or not. In humans, flow-inducing situations 
span from physically and cognitively demanding activities, e.g. rock climbing, to mostly cognitively demanding situations, e.g. chess playing or reading, depending on individual preferences and skills. It has been shown that scales differentiating between internal flowinducing tasks (e.g. thinking) and external flow-inducing tasks (e.g. playing sports) are highly correlated but still separate constructs as a model treating them as separate fitted the data significantly better than a model treating them as one construct (Marty-Dugas \& Smilek, 2019). Some species or individuals may require both cognitive and physical challenge to be induced into a flow state whereas others may be able (or better able) to achieve this solely through cognitive challenge. It is thus relevant to consider the level of physical activity when designing a flow-inducing task. It is also relevant to consider that the boundary between physical and cognitive challenge is a fuzzy one, especially as we compare across species with divergent abilities. Activities (e.g. running in place) considered mostly physical for one species (e.g. humans) may offer enough of a cognitive component for other species (e.g. mice) that they become elective and thus intrinsically motivated (Meijer \& Robbers, 2014). It remains to be seen whether such activities are additionally capable of inducing (full-blown) flow states in these species.

Decisions should be based on considerations of the species (e.g. rhinos may have a different physical activity profile than monkeys), breeds within one species (e.g. mastiffs versus poodles), age (e.g. adult cows versus calves) and the individual per se (Dog A versus Dog B). While individual preferences and differences are paramount to induce flow, the central design principles of potential flow-inducing tasks should be derived by considering the species' ecological niche and the challenges they face in it. In the case of cooperative hunters, e.g. wolves, wild dogs or some marine mammals, simulation of cooperative hunts may be promising to induce flow. For example, zoos moving artificial prey on a rope to induce hunting and thus to keep their animals active may vary the challenge of hunting the 'prey', 
e.g. by changing its speed, rendering its moves unpredictable, and so on. However, since cooperative hunting is a group activity, it cannot be adapted to one single individual, and one may thus induce flow in one or a few but not necessarily in all animals of a group. A similar approach could be applied to herding dogs, albeit in an individual setting. One proposal for such an approach would involve simulating the herding experience on a computer touch screen in which the dog 'herds' moving dots by tapping the screen in different locations. Comparable to the example of the cooperative hunters, the difficulty of the task can be modulated by increasing the number of dots, the speed and complexity with which the dots move or the initial degree of dispersal. The degree of challenge can be augmented by simply modulating one parameter, e.g. increasing the speed of dot movement, or by introducing additional challenges, e.g. allowing single dots to 'react' differently thus requiring the dog to split its attention to be successful. Ideally, the task records the performance of the subject, gives them immediate feedback and automatically adapts to their progress by increasing the complexity of the task.

In species that neither hunt nor herd flow needs to be induced differently. For pigs, an intensively farmed species, we suggest a task based on odours considering the highly developed olfactory capabilities of this species. For example, one could use a modified holeboard (e.g. Roelofs, Nordquist \& van der Staay, 2017), where a naturally rewarding odour, e.g. from truffles or acorns, originates from one of the holes. The pig then needs to use the gradient of the odour to locate the source. Once they have poked their snout through the target hole (the target behavioural response), an odour emanates from a different hole effectively presenting the pig with their next challenge. The task resembles the Japanese 'Whac-A-Mole' game where a human needs to hit a mole popping out of one of several holes with a hammer. Once the mole has been hit, another mole appears from a different hole, which now must be hit. For pigs, the difficulty of the task could be adapted by increasing the 
distance between consecutive scented holes, the strength of the odour, other odours used to distract from the target, etc. The advantage of using scent would be that they are naturally appetitive but do not allow a consummatory phase, thus avoiding the classical properties of extrinsic motivation. However, the volatile nature of odours makes them hard to control and presents practical challenges. Alternatively, the principle of the proposed task set-up could be used with other stimuli such as sounds or flashing lights instead of odours.

Considering pigs and other farmed animals, most of them are young, often even prepubertal.

Thus, their developmental stage, including their cognitive development, needs to be taken into account when aiming to induce flow in farmed animals. However, from humans we know that children experience flow, for example when playing games (Inal \& Cagiltay, 2007; Mesurado \& Richaud de Minzi, 2014), indicating that experiencing flow plays a role in young individuals too. 'Playgrounds' with a variety of tasks to address the dispositions of different individuals and with different challenge levels to address different skill levels among individuals, may be a way forward to induce flow in farmed and other young captive animals.

Besides the importance of regarding a species' ecological niche when thinking about the type and quality of flow-inducing activities, it is also important to consider that species may differ quantitatively in how important flow is for them. We thus need to recognise that the motivation to experience flow, the rewarding value of it and hence the potential that flow has to promote positive welfare may vary across species and individuals.

(a) Environmental enrichment and flow induction

The use of environmental enrichment to improve animal welfare in captive species has a long tradition and has consequently received much research attention (Young, 2003). Whereas most enrichment is aimed at providing captive animals with the opportunity to express 
natural behaviour, its potential to stimulate animals cognitively has also been investigated

474 (Clark, 2017). We believe that enrichment that fulfils the criteria for flow induction, as described above, has great potential to induce flow in captive animals. For example, the above-mentioned playgrounds can be seen as a kind of enrichment, too. However, whereas approaching flow induction from the standpoint of upgrading existing enrichment may lead to important insights regarding flow in animals, it may be additionally necessary to advance the field by taking a different point of departure, one that begins by reflecting on what may induce flow in a specific species or clade.

(b) Chronic stress

Animals in captivity are exposed to various sources of stress (Morgan \& Tromborg, 2007).

This raises the question whether and how stress impacts on a subject's ability to achieve a flow state. From humans we know that intermediate arousal levels are optimal: heightened arousal seems to enhance flow whereas too much arousal undermines it (Peifer et al., 2014; Tozman et al., 2015). However, how chronic stress impacts on flow is less well known and we can only speculate about this relationship in non-human animals. It is possible that chronic stress inhibits the ability of an animal to achieve flow because they may not be able or willing to focus fully on the flow-inducing task if other stimuli require their attention. Moreover, chronic stress can lead to depression-like states including anhedonia (Stepanichev et al., 2016), and an anhedonic subject may not be motivated to start engaging with the task. However, entering a flow state may also provide a useful mechanism to cope with stressful circumstances. Whether or not experiencing flow helps to cope with adverse conditions may depend on the subject's coping style. For example, a reactive individual with high levels of behavioural flexibility (Koolhaas et al., 1999) may be better able to master progressively more difficult challenges and enter a flow state to cope with stress, whereas a more proactive 
individual with high levels of routine formation (Koolhaas et al., 1999) may experience frustration using this strategy.

500

(c) Flow proneness and personality traits

502 In humans, flow proneness, i.e. the tendency to experience flow, has been shown to be affected by personality traits. For example, it has been positively correlated with extraversion, conscientiousness and playfulness and negatively correlated with neuroticism and agreeableness [for playfulness (Ross \& Keiser, 2014; Jin, 2012); for conscientiousness and neuroticism (Ullén et al., 2012)]. In addition, the human literature has introduced the concept of the autotelic personality to describe individuals who tend to seek out intrinsically rewarding activities (Csikszentmihalyi, 1975). Psychometric tools have been developed to operationalise autotelic personality and flow propensity, and recent work finds that positive associations between autotelic personality and well-being are mediated by experiences of flow (Tse, Nakamura \& Csikszentmihalyi, 2020). However, the intensity of a flow experience is less affected by characteristics of the person and more by the flow-inducing situation (Kocjan \& Avsec, 2017). To what extent flow tendency and intensity are affected by individual differences in non-human animals remains a subject for future research. Furthermore, when evaluating flow proneness in animals, one must consider the possibility of rather large species differences. Flow may be a powerful avenue for enhancing welfare for some species but not others.

\section{(2) Flow assessment}

To check whether flow has been successfully induced, we need to be able to identify it. As

521 with flow induction, we suggest deriving ways to assess flow from our understanding of flow

522 in humans (Table 1). Flow can be characterised by certain subjective experiences, including 
523 (but not limited to) loss of reflective self-consciousness, loss of sight of oneself,

524 effortlessness and a heightened sense of control and competence (Csikszentmihalyi, 1990;

525 van der Linden et al., 2021). Unfortunately, non-human animals cannot verbally express their

526 feelings or subjective experiences, making it impossible to study the characteristics of flow

527 experiences with most of the methodological approaches used in humans. However, two of

528 the characteristics to assess flow can be applied to non-human animals: resistance to external

529 distraction and time distortion.

530

531

(a) Resistance to distraction

532 We propose to measure the degree of engagement or absorption in an activity by introducing a series of graded stimuli intended to distract the subject from performing the activity. The ability to ignore increasingly attractive stimuli (e.g. strange noises, moving objects, food rewards) will indicate the degree to which the individual is having an autotelic, intrinsically rewarding experience - one of the characteristic outcomes of the flow state. Thus, we suggest a novel test in which intrinsic motivation is measured by how difficult it is to stop the individual from performing the task. Once the subject has demonstrated a willingness to remain engaged, stimuli are introduced to test the degree of absorbed engagement in the task. The stimuli increase in intensity throughout the course of the activity, starting from mild (e.g. 541 playback of sounds) and ranging to strong (e.g. food rewards).

(i) What to consider

544 Our proposal to operationalise flow by incorporating into its definition a resistance to distraction forces us to consider other psychological states that may include a similar degree of absorption in an activity, e.g. obsession, addiction and stereotypic behaviour. Below we

547 describe these different phenomena and how to differentiate between them, if possible. 
548 The American Psychological Association defines an obsession as "recurrent and persistent

549 thoughts, urges, or images that are experienced as intrusive and unwanted" (American

550 Psychiatric Association, 2013, p. 235). Since one of the main goals of cultivating flow in

551 animals is to improve their affective wellbeing, cultivating it in a way that avoids obsession,

552 and the associated anxiety, distress or discomfort, is critical to its implementation for the

553 purposes of animal welfare. Whereas obsessions over thoughts, ideas or images, such as

554 irrational concerns over contamination, are not relevant to the current discussion, cultivation

555 of flow states in animals may well involve engendering strong impulses to perform certain

556 activities. Any activity that generates such strong impulses may develop into what social

557 psychologists call 'passions', defined as 'a strong inclination toward an activity that people

558 like, that they find important, and in which they invest time and energy" (Vallerand et al.,

559 2003, p. 757). In their studies of passion, Vallerand et al. (2013) provide empirical evidence

560 for a dualistic conceptualisation of passion into 'harmonious passion' and 'obsessive

561 passion'. Although they define these concepts largely by the way the passion is internalised

562 into the subject's identity, something that is either irrelevant or unobtainable in non-human

563 animals, features of the distinction may yet provide useful guidance. Harmonious passions

564 are ones in which the subject is in control and engagement in the activity is flexible, leading

565 to minimal conflict between the passionate activity and other activities in the subject's life.

566 By contrast, obsessive passions are ones in which an internal compulsion leads the subject to

567 engage in the activity even when they should not, thus causing conflict between the

568 passionate activity and other important activities. Therefore, in attempting to cultivate flow in

569 animals for the purpose of improving welfare, care should be taken to avoid achieving a

570 degree of resistance to distraction that ultimately renders the animal obsessively passionate

571 and incapable of engaging in other important daily activities. For example, while ignoring a 
tasty treat in an otherwise well-fed dog may be a good indicator of flow, refusal to eat normal meals may indicate a dog that has developed an obsessive passion.

Another state capable of engendering a degree of absorption resistant to distraction is addiction. Addiction is the most severe form of substance-use disorder and is described as a state of uncontrolled psychological or physical dependence (or both) on a chemical substance or behaviour despite harmful consequences or impairment of daily life function (American Psychiatric Association, 2013). While aspects concerning dependence on a chemical substance are irrelevant to this discussion, the term is also commonly applied to behavioural disorders such as sex, internet, or gambling addiction. The topic of online gaming has challenged the conceptual boundary between the flow state and addiction. Online gaming has experienced enormous growth in recent years and represents a sizable portion of economic activity, with highly skilled players able to make lucrative careers out of their play. As an activity, it lends itself extremely well to the cultivation of the flow state. The majority of studies demonstrate a positive association between the degree of flow and addictive tendencies in online gaming (Chou \& Ting, 2003; Wu, Scott \& Yang, 2013), as well as physical activities like surfing (Partington, Partington \& Olivier, 2009), and further show a stronger positive association in the most skilled individuals. Thus, addiction is a valid concern for any attempt to induce flow in animals. While flow-inducing provisions can be removed more easily from animals than from humans who are more capable of providing it for themselves, denied access to a desired provision is aversive and should not be taken lightly if an addiction starts to develop.

Another behavioural concern involving resistance to distractibility is stereotypic animal behaviour ( $\mathrm{SAB})$. SAB is well studied in captive animals and is typically seen as animal welfare concern (Mason \& Latham, 2004), even though the various proposed mechanisms underlying this behavioural disorder are associated with different types of concerns (Mason, 
2006; Würbel, 2006; Würbel, Bergeron \& Cabib, 2006). Once established, SAB is difficult to interrupt and discourage (Mason, 1991). It becomes resistant to distractors, posing the question what differentiates $\mathrm{SAB}$ from behaviour performed when in flow. In contrast to obsession and addiction that have been shown to be associated with the experience of flow in humans, SAB and flow differ fundamentally in both the characteristics of the performed behaviour and the context in which they develop. Whereas SAB is, by definition, repetitive and invariant (reviewed by Mason, 1991), behaviour performed during a flow state needs to be highly flexible to adapt to the progressively evolving challenges. Moreover, the context in which animals develop stereotypic behaviours differs greatly from the context that elicits a flow state. SAB usually starts to develop when the animal is prevented from performing highly motivated appetitive and/or consummatory behaviour (Clubb, Vickery \& Latham, 2006). By contrast, a flow-inducing context allows the subject to have control over the situation, is challenging and flexibly adapts to the subject's advancing skill. In short, SAB develops in contexts of deprivation while flow develops in contexts that offer opportunities for skill enrichment.

In sharing resistance to distraction, flow can be both conceptually and practically difficult to distinguish from obsession, addiction, and stereotypy. Differentiating them involves invoking a functionalist perspective that examines how the activity impacts the overall well-being and quality of life of the individual. While typically discussed in a positive context, work on the “dark side" of flow (Partington et al., 2009) or "dark flow" (Dixon et al., 2018) has recognised the potential negative impact the cultivation of flow states can also have. Indeed, formative discourse on flow recognised that, "the self becomes captive of a certain kind of order and is then unwilling to cope with the ambiguities of life" (Csikszentmihalyi, 2002, p. 62). In this way, engaging in flow-inducing activity can lead to neglect of essential life- 
sustaining activities. Thus, animal caretakers attempting to cultivate flow states should carefully monitor behaviour for notable changes that may indicate a collapse into dark flow.

625 Altered time perception is one of the key characteristics of a flow experience

626 (Csikszentmihalyi, 1975, 1990; van der Linden et al., 2021). We tend to judge time as 627 passing more quickly or as 'flying by' when we experience flow (Christandl, Mierke \& Peifer, 2018; Conti, 2001), and we tend to judge time as passing more slowly or 'dragging' when we are bored (Fahlman et al., 2013; Watt, 1991). In humans, time distortion is typically assessed by interviewing the study subjects about how quickly time seemed to pass while being in flow (passage of time judgement; Jones 2019) or, more specifically, by asking them to judge how much time has elapsed from the beginning to the end of their flow experience. As this methodological approach relies on verbal communication, it cannot be used in the study of non-human animals, but other approaches to study time perception can overcome this challenge.

Retrospective time perception can, for example, be investigated with the Temporal Bisection Task, which has been translated from humans to non-human animals, including mice (Akdoğan \& Balci, 2016), rats (Church \& Deluty, 1977) and dogs (Macpherson \& Roberts, 2017). In this task, subjects are trained to associate a long stimulus, e.g. a long tone, with an operant response, e.g. pressing the right lever, and to associate a shorter stimulus, e.g. a shorter tone, with a different operant response, e.g. pressing the left lever. After subjects have mastered the association, they are given tones of intermediate length thus presenting them with a perceptual dilemma. Whether subjects go right or left therefore informs us about whether they perceived the intermediate tone as long or short. 
645 Prospective time perception can be assessed in non-human animals as well. In the Peak

646 Procedure, for example, subjects first learn to show an operant response (e.g. pressing a

647 button for food) to a conditioned stimulus (e.g. onset of a light or tone) only after the stimulus

648 has been on for a specified interval (e.g. 30 s) (Meck, 1996). In fixed-interval trials, subjects

649 receive reinforcement (i.e. food) only when they press the button after the specified interval

650 has elapsed. Then, during probe trials, the duration of the signal is extended (e.g. up to 90 s)

651 without reinforcement allowing the experimenter to observe the gradual increase in response

652 rate as it reaches a maximum at the time when the subject expects reinforcement. This reveals

653 their perceived sense of time and is referred to as the peak time. The aim of the task is

654 essentially to ask the subjects, "Tell me when 30 seconds are over" and has been translated to

655 pigeons (Aum, Brown \& Hemmes, 2004), mice (Balci et al., 2008) and rats (Kaiser, 2008).

656

657 (i) What to consider

658 As for reduced distractibility, the limitations of time distortion as an indicator of flow need to

659 be discussed. Unfortunately, even though time during flow is usually compressed, i.e. flies

660 by, the opposite is also possible: "Intense attention to detail [...] can also make time feel as

661 though it is standing still" (Danckert \& Eastwood, 2020, p. 174). The fact that the

662 relationship between a flow experience and time distortion can go in both directions is less of

663 a problem in human studies since the expansion of time during flow has different qualities:

664 liberation from time during flow compared to time dragging when bored (Danckert \&

665 Eastwood, 2020). This difference in quality can be easily assessed in humans but may render

666 the interpretation of the results from time-perception tasks such as the Temporal Bisection

667 Task and the Peak Procedure challenging. However, it has been suggested that time stands

668 still during the flow experience whereas afterwards it feels like it has been flying by

669 (Csikszentmihalyi, 1990); as the proposed time-perception tasks would only be performed 
670 after a flow experience, we would expect animals to respond as if time was flying by as

671 hypothesised above.

672 Unfortunately, the assessment of time distortion once a flow experience has elapsed is

673 challenging since it is unclear for how long the effect lasts. Whereas we can ask humans how

674 they perceived the time during their flow experience retrospectively, the proposals outlined

675 above rely on the flow experience producing a lasting effect that does not vanish with the

676 start of the subsequent testing procedure in non-human animals. However, to date this

677 limitation is due to a lack of research rather than a conceptual hurdle and we are thus

678 optimistic to gather insights into the duration of time distortion in the future.

679

680

(3) Identifying the behavioural, physiological and neurophysiological signature of flow

681

Once flow-like states in non-human animals have been validated by measures of

682

distractibility and time distortion, this opens the possibility to explore other correlates less

683

accessible to investigation, whether behavioural, physiological or neurophysiological.

684

Identifying correlates with strong discriminant validity could be used further to identify flow-

685

like states in animals in situations not conducive to measuring distractibility or time

686

distortion.

687

Flow assessments based on self-report play the largest role in human studies. Only a few

688

studies have explored behavioural correlates of flow experiences, mainly with children

689

involved in musical activities (Addessi, Ferrari \& Carugati, 2015; Custodero, 2005). More

690

recently, the Flow Observational Grid has been developed and validated in people playing

691

video games (Tordet et al., 2021). The grid consists of the three dimensions concentration,

692 enjoyment and frustration, which are each rated on a scale from 0 to 3 (or 4 ) by the observers.

We suggest that such an approach could be easily applied to non-human animals, using, for example, the methodology of Qualitative Behaviour Assessment (QBA), which is well 
established in animal welfare science (Wemelsfelder et al., 2001). In QBA, the qualitative expressions of an animal's behaviour are described using adjectives (e.g. relaxed, frustrated) and these expressions are then quantified using Visual Analogue Scales. This approach is comparable with the Flow Observational Grid and thus offers a suitable starting point in the search for behavioural correlates of flow in non-human animals. In addition, we suggest detailed analysis of body postures and facial expressions, thereby not only focusing on durations and frequencies, but also the simultaneous occurrence of postures (e.g. Hintze et $a l ., 2020)$ and their sequence over time (e.g. Asher et al., 2009).

Physiological correlates of flow have been explored in humans (Keller et al., 2011; Knierim et al., 2018; de Manzano et al., 2010; Peifer et al., 2014) and may also be fruitful in animals to identify physiological patterns indicative of flow-like states. In humans, flow seems to be associated with a moderate co-activation of both parasympathetic and sympathetic branches of the autonomic nervous system (de Manzano et al., 2010; Peifer et al., 2014; Tozman et al., 2017). However, the relationship between flow and sympathetic arousal is U-shaped whereas flow and parasympathetic activity are linearly and positively correlated (de Manzano et al., 2010; Peifer et al., 2014). This supports the notions that (i) too much and too little arousal/challenge inhibit flow, and (ii) perceptions of effortlessness thought to be associated with parasympathetic activity increase with increasing flow. In line with the idea that coactivation of both branches supports flow states, Arhant et al., (2020) found a strong positive correlation between sympathetic (Heart Rate, HR) and parasympathetic (Root mean square of successive RR interval differences, RMSSD) measures in dogs that were gradually introduced to a game but a negative correlation in dogs that were hastily introduced to the same game. The authors suggest that, unlike dogs that were hastily introduced to the game and thus prone to frustration, dogs from the first group developed a better match between challenge and skills and perhaps experienced a flow-like state, characterised by a similar 
physiological signature as found previously in humans (Arhant et al., 2020). While further research is necessary, co-activation of the autonomic nervous system branches may well mediate the effort paradox widely discussed as a hallmark of human flow in which energetic effort is high but perceived effort is lower than expected (Harris, Vine \& Wilson, 2017).

Several studies conducted in humans have investigated the neurophysiological correlates of flow. Relevant to using resistance to distraction as an assessment tool, flow has been associated with neurophysiological indices that suggest improved top-down attentional control, a prerequisite for the ability to ignore a distraction. Regions associated with the multiple demand network, which regulate top-down attentional control, demonstrated greater activation during flow states (Ulrich et al., 2014; Ulrich, Keller \& Grön, 2016). Van der Linden et al. (2021) propose further investigation into dopaminergic and noradrenergic neuromodulatory systems as well as the salience, central executive, and default-mode restingstate networks to provide neurobiological accounts for subjective aspects of the flow experience, such as deciding whether to stay on task or move on to something else, shown to be regulated by the noradrenergic system. Another study reported greater dopamine D2 receptor availability in individuals prone to flow states (de Manzano et al., 2013). Given that greater D2 receptor availability has been associated with greater impulse control and response inhibition, this property of dopaminergic regulation may mediate an individual's ability to ignore distractions during flow. Given the practical challenges of inducing flow in animals in a neuroimaging setting, further investigation on the neurophysiological correlates of flow in animals could follow the strategy of de Manzano et al. (2013) by studying animals prone to experiencing flow in their daily lives.

Once the experience of flow has been validated, longer-lasting effects of flow states can be investigated. From studies in humans we know that the experience of flow leads to positive affect in the short term (Rogatko, 2009) and that it is correlated with high life satisfaction and 
750

751

752

753

754

755

756

757

758

759

760

761

762

763

764

765

766

767

hedonic balance in the long term (Bassi et al., 2014). Flow may affect mood in non-human animals too, which may be assessed in a Judgement Bias Task where more optimistic subjects judge ambiguous stimuli more positively than pessimistic subjects (Harding, Paul \& Mendl, 2004).

\section{CONCLUSIONS}

(1) While a large part of human enjoyment occurs through engaging in intrinsically rewarding activities, we have a limited understanding of intrinsic reward in non-human animals and thus no way of systematically providing it. The time is ripe to translate the concepts of flow and intrinsic motivation to non-human animals.

(2) Studying flow in non-human animals will advance methodological approaches to intrinsic motivation beyond self-report, thereby advancing both the fields of positive human psychology and positive animal welfare.

(3) While there are roadblocks and challenges to studying flow and intrinsic motivation in non-human animals, observations scattered across the field of biology suggest these concepts are not unique to humans.

(4) Focusing on a subset of operationalisable characteristics, namely resistance to distraction and time distortion, provides an avenue to deepen investigations of positive well-being across the animal kingdom.

\section{ACKNOWLEDGEMENTS}

We would like to thank Jean-Loup Rault for his valuable comments on an earlier version of this review. 


\section{REFERENCES}

Addessi, A. R., Ferrari, L. \& Carugati, F. (2015). The flow grid: a technique for observing and measuring emotional state in children interacting with a flow machine. Journal of New Music Research 44(2), 129-444.

Akdoğan, B. \& Balci, F. (2016). Stimulus probability effects on temporal bisection performance of mice (Mus musculus). Animal Cognition 19, 15-30.

American Psychiatric Association (2013). Anxiety disorders. Diagnostic And Statistical Manual Of Mental Disorders 5.

Arhant, C., Altrichter, B., Lehenbauer, S., Waiblinger, S., Schmied-Wagner, C. \& Yee, J. (2020). Balancing skill against difficulty - behavior, heart rate and heart rate variability of shelter dogs during two different introductions of an interactive game. Applied Animal Behaviour Science 232, 105141.

Asher, L., Collins, L. M., Ortiz-Pelaez, A., Drewe, J. A., Nicol, C. J. \& Pfeiffer, D. U. (2009). Recent advances in the analysis of behavioural organization and interpretation as indicators of animal welfare. Journal of the Royal Society Interface 6,1103-19.

Aum, S. W., Brown, B. L. \& Hemmes, N. S. (2004). The effects of concurrent task and gap events on peak time in the peak procedure. Behavioural Processes $\mathbf{6 5}, 43-56$.

Balci, F., Ludvig, E. A., Gibson, J. M., Allen, B. D., Frank, K. M., Kapustinski, B. J., Fedolak, T. E. \& Brunner, D. (2008). Pharmacological manipulations of interval timing using the peak procedure in male $\mathrm{C} 3 \mathrm{H}$ mice. Psychopharmacology 201, 67-80.

Baluku, M. M., Kikooma, J. F. \& Otto, K. (2018). Positive mindset and entrepreneurial outcomes: the magical contributions of psychological resources and autonomy. Journal of Small Business and Entrepreneurship 30(6), 473-98.

Bassi, M., Steca, P., Monzani, D., Greco, A. \& Delle Fave, A. (2014). Personality and optimal experience in adolescence: implications for well-being and development. 
795

796

797

798

799

800

801

802

803

804

805

806

807

808

809

810

811

812

813

814

815

816

817

818

Bernardi, N. F., Bellemare-Pepin, A. \& Peretz, I. (2018). Dancing to 'groovy' music enhances the experience of flow. Annals of the New York Academy of Sciences 1423, 415-26.

Blois-Heulin, C., Rochais, C., Camus, S., Fureix, C., Lemasson, A., Lunel, C., Bezard, E. \& Hausberger, M. (2015). Animal welfare: could adult play be a false friend? Animal Behavior and Cognition 2(2), 156-85.

Broom, D. M. (2015). Sentience and pain in relation to animal welfare. Pp. 3-7 in Proceedings of XVII International Congress on Animal Hygiene. Košice: International Society for Animal Hygiene.

Burghardt, G. M. (2010). Defining and recognizing play. Pp. 10-18 in The Oxford Handbook of the Development of Play, edited by Nathan, P. and Pellegrini, A. New York: Oxford University Press.

Cantor, N. \& Sanderson, C. A. (1999). Life task participation and well-being: the importance of taking part in daily life. Pp. 230-43 in Well-being: The Foundations of Hedonic Psychology, edited by Kahnemann, D., Diener, E., \& Schwarz, N. New York: Russell Sage Foundation.

Chirico, A., Serino, S., Cipresso, P., Gaggioli, A. \& Riva, G. (2015). When music 'flows'. state and trait in musical performance, composition and listening: a systematic review. Frontiers in Psychology 6, Article 906.

Chou, TJ. \& Ting, CC. (2003). The role of flow experience in cyber-game addiction. CyberPsychology \& Behavior 6(6), 663-75.

Christandl, F., Mierke, K. \& Peifer, C. (2018). Time flows: manipulations of subjective time progression affect recalled flow and performance in a subsequent task. Journal of Experimental Social Psychology 74, 246-56. 
819 Church, R. M. \& Deluty, M. Z. (1977). Bisection of temporal intervals. Journal of Experimental Psychology: Animal Behavior Processes 3(3), 216-28.

821

Clark, F. E. (2011). Great ape cognition and captive care: can cognitive challenges enhance well-being? Applied Animal Behaviour Science 135(1-2), 1-12.

Clark, F. E. (2017). Cognitive enrichment and welfare: current approaches and future directions. Animal Behavior and Cognition 4(1), 52-71.

Clubb, R., Vickery, S. \& Latham, N. (2006). Motivation and motivational explanations for stereotypies. P. 12 in Stereotypic Animal Behaviour, edited by Mason, G. \& Rushen, J. Oxfordshire: CAB International.

Conti, R. (2001). Time flies: investigating the connection between intrinsic motivation and the experience of time. Journal of Personality 69(1), 1-26.

Craig, A. D. (2009). How do you feel - now? the anterior insula and human awareness. Nature Reviews Neuroscience 10, 59-70.

Csikszentmihalyi, M. (1975). Beyond Boredom and Anxiety: The Experience of Play in Work and Games. San Francisco: Jossey-Bass Publishers.

Csikszentmihalyi, M. (1990). Flow: The Psychology of Optimal Experience. New York: Harper and Row.

Csikszentmihalyi, M. (2002). Flow: The Classic Work on How to Achieve Happiness. London: Random House.

Csikszentmihalyi, M. (2006). Introduction. Pp. 3-14 in A life worth living, edited by Csikszentmihalyi, M. \& Csikszentmihalyi, I. S. New York: Oxford University Press.

Csikszentmihalyi, M., Abuhamdeh, S. \& Nakamura, J. (2014). Flow. Pp. 227-38 in Flow and the Foundations of Positive Psychology, edited by Csikszentmihalyi, M. Dordrecht: Harcourt.

Csikszentmihalyi, M. \& Asakawa, K. (2016). Universal and cultural dimensions of optimal 

experiences. The Japanese Psychological Research 58(1), 4-13.

Custodero, L.A. (2005). Observable indicators of flow experience: a developmental perspective on musical engagement in young children from infancy to school age.Music Education Research 7(2), 185-209.

Damasio, A. R. (1999). The Feeling of What Happens: Body and Emotion in the Making of Consciousness. New York: Harcourt.

Danckert, J. \& Eastwood. J. D. (2020). Just go with the flow. Pp. 164-86 in Out of my skull. The psychology of boredom, edited by Danckert, J. \& Eastwood, J. D. Cambridge, Massachusetts: Harvard University Press.

Dashiell, J. F. (1925). A quantitative demonstration of animal drive. Journal of Comparative Psychology 5(3), 205-8.

Deci, E. L. (1971). Effects of externally mediated rewards on intrinsic motivation. Journal of Personality and Social Psychology 18(1), 105-15.

Deci, E. L. \& Ryan, R. M. (2009). Intrinsic motivation. The Corsini Encyclopedia of Psychology 1-2.

de Jonge, F. H., Tilly, S. L., Baars, A. M. \& Spruijt, B. M. (2008). On the rewarding nature of appetitive feeding behaviour in pigs (Sus Scrofa): Do domesticated pigs contrafreeload? Applied Animal Behaviour Science 114, 359-72.

de Manzano, Ö., Cervenka, S., Jucaite, A., Hellenäs, O., Farde, L. \& Ullén, S. (2013). Individual differences in the proneness to have flow experiences are linked to dopamine D2-receptor availability in the dorsal striatum. NeuroImage 67, 1-6..

de Manzano, Ö., Theorell, T., Harmat, L. \& Ullén, F. (2010). The psychophysiology of flow during piano playing. Emotion 10(3), 301-11.

Diener, E. (2000). Subjective well-being: the science of happiness and a proposal for a national index. American Psychologist 55, 34-43. 
Diener, E., Suh, E. M., Lucas, R. E. \& Smith, H. L. (1999). Subjective well-being: three decades of progress. Psychological Bulletin 125(2), 276-302.

Dixon, M. J., Stange, M., Larche, C. J., Graydon, C., Fugelsang, J. A. \& Harrigan, K. A. (2018). Dark flow, depression and multiline slot machine play. Journal of Gambling Studies 34, 73-84.

Fahlman, S. A., Mercer-Lynn, K. B., Flora, D. B. \& Eastwood, J. D. (2013). Development and validation of the multidimensional state boredom scale. Assessment 20(1), 68-85.

Fisher, R. (1993). Social desirability bias and the validity of indirect questioning. Journal of Consumer Research 20, 303-15.

Franks, B. (2012). Engaging in effectiveness: highlighting the role of challenge in well-being and welfare.

Franks, B. \& Higgins, E. T. (2012). Effectiveness in humans and other animals: a common basis for well-being and welfare. Pp. 285-346 in Advances in Eperimental Social Psychology. Vol. 46, edited by Zanna, M. P., Devine, P., Olson, J. M. \& Plant, A. San Diego: Elsevier.

Freud, S. (1962). The Ego and the Id. New York: Norton.

Goldstein, R. Z., Craig, A. A., Bechara, A., Garavan, H., Childress, A. R., Paulus, M. P. \& Volkow, N. D. (2009). The neurocircuitry of impaired insight in drug addiction. Trends in Cognitive Sciences 13(9), 372-80.

Gray, S., Clark, F., Burgess, K., Metcalfe, T., Kadijevic, A., Cater, K. \& Bennett, P. (2018). Gorilla game lab: exploring modularity, tangibility and playful engagement in cognitive enrichment design. P. Article 6 in Proceedings of the Fifth International Conference on Animal-Computer Interaction.

Gruber, M. J., Gelman, B. D. \& Ranganath, C. (2014). States of curiosity modulate hippocampus-dependent learning via the dopaminergic circuit. Neuron 84, 486-96. 
Hagen, K. \& Broom D. M. (2004). Emotional reactions to learning in cattle. Applied Animal Behaviour Science 85, 203-13.

Han, S. (1988). The relationship between life satisfaction and flow in elderly korean immigrants. Pp. 138-49 in Optimal experience: psychological studies of flow in consciousness, edited by Csikszentmihalyi, M. \& Csikszentmihalyi, I. S. New York: Cambridge University Press.

Harding, E. J., Paul, E. S. \& Mendl, M. (2004). Cognitive bias and affective state. Nature 427, 312.

Harris, D. J., Vine, S. J. \& Wilson, M. R. (2017). Is flow really effortless? The complex role of effortful attention. Sport, Exercise, and Performance Psychology 6(1), 103-14.

Harris, J. C. (1978). Play and enjoyment: perspectives and implications. Harris, JC 29(1), $60-72$.

Held, S. D. E. \& Špinka, M. (2011). Animal play and animal welfare. Animal Behaviour 81(5), 891-99.

Hintze, S., Maulbetsch, F., Asher, L. \& Winckler, C. (2020). Doing nothing and what it looks like: inactivity in fattening cattle. PeerJ 8, e9395.

Holliman, A. J., Revill-Keen, A. \& Waldeck, D. (2020). University lecturers' adaptability: examining links with perceived autonomy support, organisational commitment, and psychological wellbeing. Teaching Education.

Hull, C. L. (1943). Principles of Behavior: An Introduction to Behavior Theory. New York: Appleton Century Company.

Inal, Y., \& Cagiltay, K. (2007). Flow experiences of children in an interactive social game environment. British Journal of Educational Technology 38(3), 455-64.

Inglis, I. R., Forkman, B. \& Lazarus, J. (1997). Free food or earned food? A review and fuzzy model of contrafreeloading. Animal Behaviour 53(6), 1171-91. 
Jamieson, D. (2018). Animal agency. The Harvard Review of Philosophy 25, 111-26.

Jensen, G.D. (1963). Preference for bar pressing over 'freeloading' as a function of number of rewarded presses. Journal of Experimental Psychology 65(5)451-54.

Jin, S. A. A. (2012). Toward integrative models of flow: effects of performance, skill, challenge, playfulness, and presence on flow in video games. Journal of Broadcasting and Electronic Media 56(2), 169-86.

Jones, L. A. (2019). The perception of duration and the judgment of the passage of time. philosophical and psychological essays on timing and time perception. Pp. 53-67 in The Illusions of Time, edited by Arstila, V., Bardon, A., Power, S.E. \& Vatakis. A. Cham: Soringer Nature Switzerland AG.

Kaiser, D. H. (2008). The proportion of fixed interval trials to probe trials affects acquisition of the peak procedure fixed interval timing task. Behavioural Processes 77, 100-108.

Kang, M. J., Hsu, M., Krajbich, I. M., Loewenstein, G., McClure, S. M., Tao-yi Wang, J. \& Camerer, C. F. (2009). The wick in the candle of learning: epistemic curiosity activates reward circuitry and anhances memory. Psychological Science 20(8), 963-73.

Kashdan, T. B., Stiksma, M. C., Disabato, D. D., McKnight, P. E., Bekier, J., Kaji, J. \& Lazarus, R. (2018). The five-dimensional curiosity scale: capturing the bandwidth of curiosity and identifying four unique subgroups of curious people. Journal of Research in Personality 73, 130-49.

Keller, J., Bless, H., Blomann, F. \& Kleinböhl, D. (2011). Physiological aspects of flow experiences: skills-demand-compatibility effects on heart rate variability and salivary cortisol. Journal of Experimental Social Psychology 47, 849-52.

Kidd, C. \& Hayden, B. Y. (2015). The psychology and neuroscience of curiosity. Neuron 88, 449-60.

Knierim, M. T., Rissler, R., Dorner, V., Maedche, A. \& Weinhardt, C. (2018). The 
psychophysiology of flow: a systematic review of peripheral nervous system features. Pp. 109-20 in Information Systems and Neuroscience, edited by Davis, F. D., Riedl, R., vom Brocke, J., Léger, P. M. \& Randolph, A. B. Cham: Springer International Publishing AG.

Kocjan, G. Z. \& Avsec, A. (2017). Bringing the psychology of situations into flow research: personality and situation characteristics as predictors of flow. Psychological Topics 26(1), 195-210.

Koolhaas, J. M., Korte, S. M., De Boer, S. F., Van Der Vegt, B. J., Van Reenen, C. G., Hopster, H., De Jong, I. C., Ruis, M. A. W. \& Blokhuis, H. J. (1999). Coping styles in animals: current status in behavior and stress-physiology. Neuroscience and Biobehavioral Reviews 23, 925-35.

Lavoie, R. \& Main, K. (2022). Optimizing product trials by eliciting flow states: the enabling roles of curiosity, openness and information valence. European Journal of Marketing 56(13), 50-77.

Lee, W. \& Reeve, J. (2013). Self-determined, but not non-self-determined, motivation predicts activations in the anterior insular cortex: an FMRI study of personal agency. Social Cognitive and Affective Neuroscience 8, 538-45.

Lee, W. \& Reeve, J. (2017). Identifying the neural substrates of intrinsic motivation during task performance. Cognitive, Affective and Behavioral Neuroscience 17, 939-53.

Lee, W., Reeve, J., Xue, Y. \& Xiong, J. (2012). Neural differences between intrinsic reasons for doing versus extrinsic reasons for doing: an FMRI study. Neuroscience Research 73, $68-72$.

Loewenstein, G. (1994). The psychology of cuiosity: a review and reinterpretation. Psychological Bulletin 116(1), 75-98.

MacAloon, J. \& Csikszentmihalyi, M. (1983). Deep play and the flow experience in rock 

climbing. Pp. 361-84 in Play, games and sports in cultural contexts, edited by Harris, J. C. \& Park, R. J. Champaign, Illinois: Human Kinetics Publishers.

971

972

973

Macpherson, K. M. \& Roberts, W. A. (2017). On the clock: interval timing and overshadowing in domestic dogs (Canis Familiaris). Journal of Comparative Psychology 131(4), 348-61.

Marty-Dugas, J. \& Smilek, D. (2019). Deep, effortless concentration: re-examining the flow concept and exploring relations with inattention, absorption, and personality. Psychological Research 83, 1760-77.

Mason, G. J. \& Latham., N. R. (2004). Can't stop, won’t stop: is stereotypy a reliable animal welfare indicator? Animal Welfare 13, S57-69.

Mason, G. J. (1991). Stereotypies : a critical review. Animal Behaviour 41, 1015-37.

Mason, G. J. (2006). Stereotypic behaviour in captive animals: fundamentals and implications for welfare and beyond. Pp. 325-56 in Stereotypic Animal Behaviour, edited by Mason, G. J. \& Rushen, J. Oxfordshire: CAB International.

McGowan, R. T. S., Rehn, T., Norling, Y. \& Keeling, L. J. (2014). Positive affect and learning: exploring the 'Eureka Effect' in dogs. Animal Cognition 17, 577-87.

McGowan, R. T. S., Robbins, C. T., Alldredge, J. R. \& Newberry, R. C. (2010). Contrafreeloading in grizzly bears: implications for captive foraging enrichment. Zoo Biology 29(4), 484-502.

Meck, W. H. (1996). Neuropharmacology of timing and time perception. Cognitive Brain Research 3, 227-42.

Meehan, C. L. \& Mench, J. A. (2007). The challenge of challenge: can problem solving opportunities enhance animal welfare? Applied Animal Behaviour Science 102, 246-61.

Meijer, J. H. \& Robbers, Y. (2014). Wheel running in the wild. Proceedings of the Royal Society B: Biological Sciences 281, 20140210. 
Mellor, D. J. (2012). Animal emotions, behaviour and the promotion of positive welfare states. New Zealand Veterinary Journal 60(1), 1-8.

Mesurado, B. \& de Minzi, M. C. R. (2014). Optimal experience in argentinean children and adolescents. Pp. 161-77 in Positive Psychology in Latin America. Cross-Cultural Advancements in Positive Psychology, edited by Castro Solano, A. Dordrecht: Spinger.

Moneta, G. B. (2012). On the measurement and conceptualization of flow. Pp. 23-50 in Advances in Flow Research, edited by Engeser, S. New York, NY: Springer New York.

Morgan, K. N. \& Tromborg, C. T. (2007). Sources of stress in captivity. Applied Animal Behaviour Science 102, 262-302.

Mulligan, M. S. (2016). Achieving flow in surgery. The Journal of Thoracic and Cardiovascular Surgery 151(6), 1435-39.

Murayama, K., Matsumoto, M., Izuma, K. \& Matsumoto, K. (2010). Neural basis of the undermining effect of monetary reward on intrinsic motivation. Proceedings of the National Academy of Sciences of the United States of America 107(49), 20911-16.

Naqvi, N. H. \& Bechara, A. (2009). The hidden island of addiction: the insula. Trends in Neurosciences 32(1), 56-67.

Nissen, H. W. (1930). A study of exploratory behavior in the white rat by means of the obstruction method. The Pedagogical Seminary and Journal of Genetic Psychology 37(3), 361-76.

Osborne, S. R. (1977). The free food (contrafreeloading) phenomenon: a review and analysis. Animal Learning \& Behavior 5(3), 221-35.

Partington, S., Partington, E. \& Olivier, S. (2009). The dark side of flow: a qualitative study of dependence in big wave surfing. The Sport Psychologist 23, 170-85.

Peifer, C., Schulz, A., Schächinger, H., Baumann, N. \& Antoni, C. H. (2014). The relation of flow-experience and physiological arousal under stress - can u shape it? Journal of 
1020

1021

1022

1023

1024

1025

1026

1027

1028

1029

1030

1031

1032

1033

1034

1035

1036

1037

1038

1039

1040

1041

Rault, J. L., Hintze, S., Camerlink, I. \& Yee J. R. (2020). Positive welfare and the like: distinct views and a proposed framework. Frontiers in Veterinary Science 7, 370.

Reid, D. (2011). Mindfulness and flow in occupational engagement: presence in doing. Canadian Journal of Occupational Therapy 78, 50-56.

Roelofs, S., Nordquist, R. E. \& van der Staay, F. J. 2(017). Female and male pigs' performance in a spatial holeboard and judgment bias task. Applied Animal Behaviour Science 191, 5-16.

Rogatko, T. P. (2009). The influence of flow on positive affect in college students. Journal of Happiness Studies 10, 133-48.

Ross, S. R. \& Keiser, H. N. (2014). Autotelic personality through a five-factor lens: individual differences in flow-propensity. Personality and Individual Differences 59, 3 8.

Ryan, R., Chirkov, V., Little, T., Sheldon, K., Timoshina, E. \& Deci, E. (1999). The american dream in russia: extrinsic aspirations and well-being in two cultures. Personality and Social Psychology Bulletin 25(12), 1509-24.

Ryan, R. M. \& Deci, E. L. (2000). Self-determination theory and the facilitation of intrinsic motivation, social development, and well-being. American Psychologist 11.

Ryff, C. D. (1989). Happiness is everything, or is it? explorations on the meaning of psychological well-being. Journal of Personality and Social Psychology 57(6), 106981.

Sato, I. (1988). Bosozoku: flow in japanese motorcycle gangs. Pp. 92-117 in Optimal experience: psychological studies of flow in consciousness, edited by Csikszentmihalyi, M. \& Csikszentmihalyi, I. S. New York: Cambridge University Press.

Schattke, K., Brandstätter, V., Geneviève, T. \& Kehr, H. M. (2014). Flow on the rocks: 
motive-incentive congruence enhances flow in rock climbing. International Journal of Sport Psychology 45(6), 603-20.

Schutte, N. S. (2020). The impact of virtual reality on curiosity and other positive characteristics. International Journal of Human-Computer Interaction 36(7), 661-68.

Sheldon, K. M. \& Kasser, T. (1998). Pursuing personal goals: skills enable progress, but not all progress is beneficial. Personality and Social Psychology Bulletin 24, 1319-31.

da Silva Vasconcellos, A., Adania, C. H. \& Ades, C. (2012). Contrafreeloading in maned

1051 wolves: implications for their management and welfare. Applied Animal Behaviour Science 140(1-2), 85-91.

Špinka, M. (2019). Animal agency, animal awareness and animal welfare. Animal Welfare 28, 11-20.

Špinka, M. \& Wemelsfelder, F. (2011). Environmental challenge and animal agency. Pp. 2743 in Animal Welfareelfare, edited by Appleby, M. C., Mench, J. A., Olsson, I. A. S. \& Hughes, B. O. Oxfordshire: CAB International.

Špinka, M. \& Wemelsfelder, F. (2018). Environmental challenge and animal agency. Pp. 3955 in Animal Welfare, edited by Appleby, M. C., Olsson, I. A. S. \& Galindo, F. Oxfordshire: $\mathrm{CAB}$ International.

Sprugnoli, G., Rossi, S., Emmendorfer, A., Rossi, A., Liew, S. L., Tatti, E., di Lorenzo, G., Pascual-Leone, A. \& Santarnecchi, E. (2017). Neural correlates of eureka moment. Intelligence 62, 99-118.

Stepanichev, M. Y., Tishkina, A. O., Novikova, M. R., Levshina, I. P., Freiman, S. V., Onufriev, M. V., Levchenko, O. A., Lazareva, N. A. \& Gulyaeva, N.V. (2016). Anhedonia but not passive floating is an indicator of depressive-like behavior in two chronic stress paradigms. Acta Neurobiologiae Experimentalis 76, 324-33.

Steward, H. (2009). Animal agency. Inquiry: An Interdisciplinary Journal of Philosophy 
Swann, C., Keegan, R. J., Piggott, D. \&a Crust, L. (2012). A systematic review of the experience, occurrence, and controllability of flow states in elite sport. Psychology of Sport and Exercise 13, 807-19.

Thissen, B. A. K., Menninghaus, W. \& Schlotz, W. (2018). Measuring optimal reading experiences: the reading flow short scale. Frontiers in Psychology 9, 2542.

Tordet, C., Erhel, S., Wodey, E., Jamet, E., Nardi, N. \& Gonthier, C. (2021). The flow observational grid: an observation-based solution to assess flow states. Journal of Happiness Studies 22, 3069-89..

Tozman, T., Magdas, E. S., MacDougall, H. G. \& Vollmeyer, R. (2015). Understanding the psychophysiology of flow: a driving simulator experiment to investigate the relationship between flow and heart rate variability. Computers in Human Behavior 52, 408-18.

Tozman, T., Zhang, Y. Y. \& Vollmeyer, R. (2017). Inverted U-shaped function between flow and cortisol release during chess play. Journal of Happiness Studies 18, 247-68.

Tse, D. C. K., Nakamura, J. \& Csikszentmihalyi, M. (2020). Beyond challenge-seeking and skill-building: toward the lifespan developmental perspective on flow theory. Journal of Positive Psychology 15(2), 171-82.

Ullén, F., de Manzano, Ö., Almeida, R., Magnusson, P. K. E., Pedersen, N. L., Nakamura, J., Csíkszentmihályi, M. \& Madison, G. (2012). Proneness for psychological flow in everyday life: associations with personality and intelligence. Personality and Individual Differences 52, 167-72.

Ulrich, M., Keller, J. \& Grön, G. (2016). Neural signatures of experimentally induced flow experiences identified in a typical FMRI block design with BOLD imaging. Social Cognitive and Affective Neuroscience 11, 496-507.

Ulrich, M., Keller, J., Hoenig, K., Waller C., \& Grön, G. (2014). Neural correlates of 

experimentally induced flow experiences. NeuroImage 86, 194-202.

1095

1096

1097

1098

1099

1100

1101

1102

1103

1104

1105

1106

1107

1108

1109

1110

1111

Vallerand, R. J., Blanchard, C., Mageau, G. A., Koestner, R., Ratelle, C., Léonard, M., Gagné, M. \& Marsolais, J. (2003). Les passions de l'ame: on obsessive and harmonious passion. Journal of Personality and Social Psychology 85(4), 756-67.

van der Linden, D., Tops, M. \& Bakker, A. B. (2021). Go with the flow: a neuroscientific view on being fully engaged. European Journal of Neuroscience 53, 947-63.

Vanderschuren, L. J. M. J. (2010). How the brain makes play fun. American Journal of Play $2,315-37$.

Van Os, J. M. C., Mintline, E. M., DeVries, T. J. \& Tucker, C. B. (2018). Domestic cattle (Bos Taurus Taurus) are motivated to obtain forage and demonstrate contrafreeloading. PLoS ONE 13(3), e0193109.

Vigors, B. (2019). Citizens' and farmers' framing of 'positive animal welfare' and the implications for framing positive welfare in communication. Animals 9, Article 147.

Watt, J. D. (1991). Effect of boredom proneness on time perception. Psychological Reports 69, 323-27.

Welzel, C. \& Inglehart, R. (2010). Agency, values, and well-being: a human development model. Social Indicators Research 97, 43-63.

Wemelsfelder, F., Hunter, T. E. A., Mendl, M. T. \& Lawrence, A. B. (2001). Assessing the 'whole animal': a free choice profiling approach. Animal Behaviour 62, 209-20.

White, R. W. (1959). Motivation reconsidered: the concept of competence. Psychological Review 66(5), 297-333.

Tsung Chiung, W., Scott, D. \& Yang, C. C. (2013). Advanced or addicted? exploring the relationship of recreation specialization to flow experiences and online game addiction. Leisure Sciences: An Interdisciplinary Journal 35(3), 203-17.

Würbel, H. (2006). Behavioural pathology - attempt at a biologically meaningful definition. 

Pp. 15-16 in Stereotypic Animal Behaviour, edited by Mason, G. J. \& Rushen, J. Oxfordshire: CAB International.

1121 Würbel, H., Bergeron, R. \& Cabib, S. (2006). The coping hypothesis of stereotypic 1122 behaviour. Pp. 14-15 in Stereotypic Animal Behaviour, edited by Mason, G. J. \& Rushen, J. Oxfordshire: CAB International.

1124 Yeates, J. W. \& Main, D. C. J. (2008). Assessment of positive welfare: a review. The 1125 Veterinary Journal 175, 293-300.

1126 Young, R. J. (2003). Environmental Enrichment for Captive Animals. Oxford: Blackwell Science Ltd. 